American Journal of Applied Sciences 4(12): 987-994, 2007

ISSN 1546-9239

(C) 2007 Science Publications

\title{
A Sliding Mode Speed Control of an Induction Motor
}

\author{
Kais JAMOUSSI, Mohamed OUALI and Hassen CHARRADI \\ Control Motor and Power Network (CMERP) \\ Engineering National School, University of Sfax (ENIS), BP W, 3038 Sfax, Tunisia
}

\begin{abstract}
Field-oriented control was combined to robust sliding mode for motor speed control. A smooth continuous function was added in order to overcome chattering caused by Sliding Mode Controller (SMC). Simulation results showed that improvement made by our approach compared to classical PID control.
\end{abstract}

Keywords Sliding mode control, Field-oriented control, Induction motor

\section{INTRODUCTION}

Induction motors were widely used in industry due to their relatively low cost and high reliability. To get high performances of these motors, several control approaches had been developed ${ }^{[1,2,3,4,5]}$ and they can be divided in two classes: Field Oriented Control (FOC) and Direct Torque Control (DTC). The principle of DTC for induction motor drives consist of controlling simultaneously stator flux and electromagnetic torque of the machine ${ }^{[7,8]}$. The DTC produces fast response and robust control AC adjustable speed drives ${ }^{[9]}$. As for with FOC technique, the rotor speed was asymptotically decoupled from rotor flux like DC motor and the speed depends linearly of torque current ${ }^{[10,19]}$. However, the performance will be degraded face to motor parameter variations or unknown external disturbances [11]. To offer control robustness with minimum complexity many strategies have been proposed in literature. See for example, the adaptive control in ${ }^{[3,12]}$, fuzzy control in ${ }^{[1,2,4]}$, robust control in ${ }^{[13]}$ and sliding mode control (SMC) in $[14,15,16]$. Recently, intelligent control had been proposed and widely applied to many control application. See for example the neural control for AC motors ${ }^{[17]}$. A combination of fuzzy control and SMC, called Fuzzy Sliding mode Control, had been proposed to overcame some problems see for example ${ }^{[1,2,18]}$. Even so, obtaining good performances by the classical FOC of induction motors was not evident due to difficulties encountered in the determination of motor parameters and the construction of the observers. In order to overcome these difficulties, the Sliding Mode Control (SMC) was adopted ${ }^{[23,14,20,16]}$, because it has many good features, such as robustness to parameter variations or load disturbances, fast dynamic response, and simplicity of design and implementation.
During sliding mode functioning, the system was forced to slide along or near the vicinity of the switching surface ${ }^{[21]}$. The system becomes then robust and insensitive to the interaction, disturbance and variation of parameters. Moreover, the SMC mode does not require an accurate model of the motor; this might necessitate only information on parameters value.

Yet, the insensitivity of the controlled system against uncertainties was guaranteed during the steady operation ${ }^{[12]}$. So, the system robustness cannot be maintained in the whole control process. To solve this problem, a preparation of the induction machine to the field-oriented control was suggested. The Proposed method includes two phases. The first one concerns the flux establishment in size and in direction, while the second was used to maintain the flux already settled by regulating the direct component of stator current. Since, the flux was constant inside the machine, a speed consign was applied. Then, speed control ensured by the sliding mode.

Moreover, it was well known that sliding mode techniques generate undesirable chattering. This problem can be remedied by replacing the switching function by a smooth continuous function ${ }^{[22,27]}$.

This paper proposes a new control FOC based algorithm using SMC for an induction motor drive.

In a second section, a description of the machine was given. The third section treats the preparation of the motor to the FOC. Sections four and five present the direct component regulation of stator current and the angular speed by means of sliding mode control. Finally, in section six the simulation results were presented and discussed.

\section{MATERIALS AND METHODS}

Description of the induction motor: Before the implementation of any control mode, it was necessary to define the function equations. 
For this purpose, an induction motor model was established using a rotating field reference $(d, q)$ (without saturation).

The equation system of the stator was ${ }^{[23][24][6]:}$

$$
\left\{\begin{array}{l}
V_{d s}=R_{s} I_{d s}+\frac{d}{d t} \psi_{d s}-\omega_{s} \psi_{q s} \\
V_{q s}=R_{s} I_{q s}+\frac{d}{d t} \psi_{q s}+\omega_{s} \psi_{d s}
\end{array}\right.
$$

As for the stator, the equation system was :

$$
\left\{\begin{array}{l}
0=R_{s} I_{d r}+\frac{d}{d t} \psi_{d r}-\omega_{r} \psi_{d r} \\
0=R_{s} I_{q r}+\frac{d}{d t} \psi_{q r}+\omega_{r} \psi_{q r}
\end{array}\right.
$$

Where $V_{s d}$ and $V_{s q}$ were the stator voltage components, $I_{s d}$ and $I_{s q}$ were the stator current components, $\psi_{q s}$ and $\psi_{d s}$ were the stator flux components, $\psi_{q r}$ and $\psi_{d r}$ were the rotor flux components. $R_{s}$ and $R_{r}$ were respectively the stator and rotor resistances.

Finally the mechanical equation was given by :

$$
J \frac{d}{d t} \omega_{m}=T_{e}-T_{r}
$$

where $J$ represent the moment of inertia.

Hence, the electromagnetic torque equation can be witten in terms of $\psi_{d r}$ and $\psi_{q r}$ as :

$$
T_{e}=\frac{L_{m}}{L_{r}+L_{m}}\left(\psi_{d r} I_{q s}-\psi_{q r} I_{d s}\right)
$$

Where $\omega_{r}=\omega_{s}-\omega_{m}$

The stator and rotor flux linkages expressions were ${ }^{[25]}$ :

$$
\left\{\begin{array}{l}
\psi_{d s}=L_{s} I_{d s}+L_{m} I_{d r} \\
\psi_{q s}=L_{s} I_{q s}+L_{m} I_{q r} \\
\psi_{d r}=L_{r} I_{d r}+L_{m} I_{d s} \\
\psi_{q r}=L_{r} I_{q r}+L_{m} I_{q s}
\end{array}\right.
$$

Where $L_{s}$ and $L_{r}$ were stator and rotor cyclic inductances, $L_{m}$ was the mutual inductance.

The rotor currents were given by: ${ }^{[23][25]}$

$$
\left\{\begin{array}{l}
I_{d r}=\frac{1}{L_{r}} \psi_{d r}-\alpha I_{d s} \\
I_{q r}=\frac{1}{L_{r}} \psi_{q r}-\alpha I_{q s}
\end{array}\right.
$$

Where $\alpha=\frac{L_{m}}{L_{r}}$

While writing Eqs (6) in (2) and assuming $\tau_{r}=L_{r} / R_{r}$, the rotor flux equations were expressed as :

$$
\left\{\begin{array}{l}
\dot{\psi}_{d r}=-\frac{1}{\tau_{r}} \psi_{d r}+\omega_{r} \psi_{q r}+\frac{L_{m}}{\tau_{r}} I_{d s} \\
\dot{\psi}_{q r}=-\omega_{r} \psi_{d r}-\frac{1}{\tau_{r}} \psi_{q r}+\frac{L_{m}}{\tau_{r}} I_{q s}
\end{array}\right.
$$

Using Eqs (8) and Eqs (5), the stator flux was given by:

$$
\left\{\begin{array}{l}
\psi_{d s}=\left(L_{s}-\alpha L_{m}\right) I_{d s}+\alpha \psi_{d r} \\
\psi_{q s}=\left(L_{s}-\alpha L_{m}\right) I_{q s}+\alpha \psi_{q r}
\end{array}\right.
$$

Some notations were considered to get some simplification, so, we consider:

$L_{l}=L_{s}-\alpha L_{m}$ and $R_{l}=R_{s}+\alpha^{2} R_{r}$.

Differentiating Eqs. (8), substituting them into Eqs. (1) and letting $\tau_{l}=L_{l} / R_{l}$ leads to :

$\left\{\begin{array}{l}\dot{I}_{d s}=\frac{\alpha}{\tau_{1} L_{1}} \psi_{d r}+\frac{\alpha}{L_{1}} \omega_{m} \psi_{q r}-\frac{1}{\tau_{1}} I_{d s}+\omega_{s} I_{q s}+\frac{1}{L_{1}} V_{d s} \\ \dot{I}_{q s}=-\frac{\alpha}{L_{1}} \omega_{m} \psi_{d r}+\frac{\alpha}{\tau_{1} L_{1}} \psi_{q r}-\omega_{s} I_{d s}+\frac{1}{\tau_{1}} I_{q s}+\frac{1}{L_{1}} V_{q s}\end{array}\right.$

Finally we get the state equations of the induction machine using. (7), (9) and (3) :

$\left\{\begin{array}{l}\dot{\psi}_{d r}=-\frac{1}{\tau_{r}} \psi_{d r}+\omega_{r} \psi_{q r}+\frac{L_{m}}{\tau_{r}} I_{d s} \\ \dot{\psi}_{q r}=-\omega_{r} \psi_{d r}-\frac{1}{\tau_{r}} \psi_{q r}+\frac{L_{m}}{\tau_{r}} I_{q s} \\ \dot{I}_{d s}=\frac{\alpha}{\tau_{1} L_{1}} \psi_{d r}+\frac{\alpha}{L_{1}} \omega_{m} \psi_{q r}-\frac{1}{\tau_{1}} I_{d s}+\omega_{s} I_{q s}+\frac{1}{L_{1}} V_{d s} \\ \dot{I}_{q s}=-\frac{\alpha}{L_{1}} \omega_{m} \psi_{d r}+\frac{\alpha}{\tau_{1} L_{1}} \psi_{q r}-\omega_{s} I_{d s}+\frac{1}{\tau_{1}} I_{q s}+\frac{1}{L_{1}} V_{q s} \\ \dot{\omega}_{m}=\frac{1}{J}\left[T_{e}-T_{m}\right]\end{array}\right.$

Since it was fully described by the equation system (10), the motor was ready to be controlled using FOC method. Nevertheless, it can be seen that equation system 10 describes the motor by complicate and non linear model. So, it was necessary to adopt the decoupling relationship means of a proper selection of state coordinates, under the simplifying hypothesis that the rotor flux was kept constant ${ }^{[23]}$.

Preparation of motor to the Field Oriented Control: Since, the decoupling condition of the feedback linearization method always holds, the parameters of the induction motor must be precisely known and accurate information on the rotor flux was required. Meantime, the dynamic behavior of the induction motor under the field-oriented or feedback linearization control techniques was quite similar to that of a separately excited DC motor, and the control effort was 
simplified. However, the performance will be degraded due to the motor parameter variations or unknown external disturbances.

To prepare the machine to the field-oriented control, two conditions should be satisfied.

- The module of the vector of flux must be constant and equal to the nominal value.

- The direction must be confused with the direct axis "d".

What was to say that the rotor flux quadrature component was equal to zero.

$$
\psi_{q r}=0 \text { or } \dot{\psi}_{q r}=0 \text { with } \psi_{q r}(0)=0
$$

This allows eliminate the terms $\psi_{q r}$ in the state Eqs.

(10), which reduces the model order to four. Indeed, the second state equation of the system (10) becomes equal to :

$$
\omega_{s}=\omega_{m}+\frac{L_{m} I_{q s}}{\tau_{r} \psi_{d r}}
$$

Which give the expression of the stator pulsation according to the variables of state gives. Then the equations of state become:

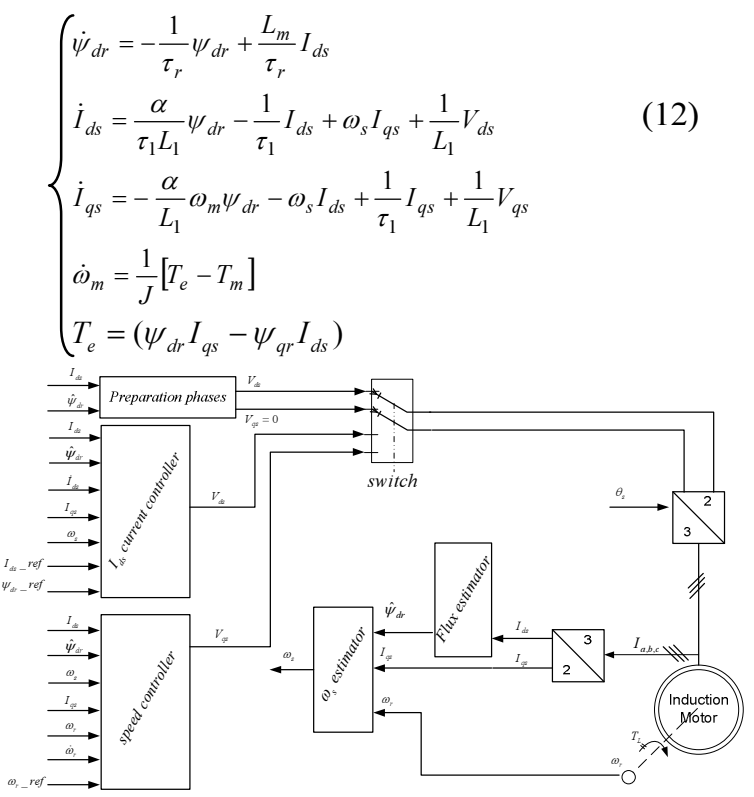

Fig.1: Bloc diagram of the field oriented control and the preparation phases

Flux establishment: In the equation system (12) it was easy to notice that the only control which acts on $\psi_{d r}$, while $\omega_{s}=0$, was $V_{d s}$ through the stator current $I_{d s}$. In order to put flux to its nominal value in a minimum time $\left(\psi_{d r}=\psi_{d r N}\right)$ it was necessary ${ }^{[26]}$ :

- To apply the maximum value of the control $\left(V_{d s}=V_{d s \max }\right)$.

- To maintain $\omega_{s}=0$ to eliminate the interaction between the currents $I_{d s}$ and $I_{q s}$. That was done by annulling of the effect of the terms $\omega_{s} I_{q s}$ and $\omega_{s} I_{d s}$ which appear in the second and the third equation of system (12). So we obtain two completely decoupled systems. The system of equations (12) will be reduced to its the first two equations was:

$\left\{\begin{array}{l}\dot{\psi}_{d r}=-\frac{1}{\tau_{r}} \psi_{d r}+\frac{L_{m}}{\tau_{r}} I_{d s} \\ \dot{I}_{d s}=\frac{\alpha}{\tau_{1} L_{1}} \psi_{d r}-\frac{1}{\tau_{1}} I_{d s}+\frac{1}{L_{1}} V_{d s}\end{array}\right.$

Since $\tau_{r}<<\tau_{1}$ (section 2), the application of the control $\left(V_{d s}=V_{d s \max }\right)$ generates a fast variation of $I_{d s}$ current. This later reaches its nominal value long before $\psi_{d r}$. Thus, the application of such command must be organized as follows:

a) As the machine coil accepts a current up to 1.2 of the nominal value $I_{d s N}$, it becomes possible to apply the control $\left(V_{d s}=V_{d s \max }\right)$ until $I_{d s}$ arrives to $1.2 I_{d s N}$, which permits to accelerate the phase of flux establishment.

b) To maintain $I_{d s}$ to $1.2 * I_{d s N}$ which involves $\dot{I}_{d s}=0$ and so $V_{d s}$ expression becomes:

$V_{d s}=-\frac{\alpha}{\tau_{r}} \psi_{d r}+\frac{L_{1}}{R_{1}} I_{d s}$.

Consequently, the first Eq. of the system (13) will be reduced to a first order equation (15):

$$
\dot{\psi}_{d r}=-\frac{1}{\tau_{r}} \psi_{d r}+1.2 \frac{L_{m}}{\tau_{r}} I_{d s N}
$$

Hence, the flux rises according to the time constant $\tau_{r}$

c) When the nominal value of $\psi_{d r}$ was reached, the following control $V_{d s}$ was applied:

$$
V_{d s}=-\frac{\alpha}{\tau_{l}} \psi_{d r N}+R_{l} I_{d s N}
$$

That permits to maintain $\psi_{d r}$ at its nominal value. Thus $\dot{\psi}_{d r}=0$ and using eq. (13), $\psi_{d r N}=L_{m} I_{d s N}$. Eq. (16) can be written:

$$
V_{d s}=\left(R_{l}-\alpha^{2} R_{r}\right) I_{d s N} .
$$

This phase was stopped when $I_{d s}$ decreases to $I_{d s}$ ref . 
In order to regulate the flux $\psi_{d r}$ around its reference value $(0.85 \mathrm{~Wb})$, the $I_{d s}$ current was maintained to its reference value.

The machine state equations were given by:

$$
\left\{\begin{array}{l}
\dot{I}_{q s}=-\frac{\alpha}{L_{1}} \omega_{m} \psi_{d r}-\omega_{s} I_{d s}+\frac{1}{\tau_{1}} I_{q s}+\frac{1}{L_{1}} V_{q s} \\
\dot{I}_{d s}=\frac{\alpha}{\tau_{1} L_{1}} \psi_{d r}-\frac{1}{\tau_{1}} I_{d s}+\omega_{s} I_{q s}+\frac{1}{L_{1}} V_{d s} \\
\dot{\psi}_{d r}=-\frac{1}{\tau_{r}} \psi_{d r}+\frac{L_{m}}{\tau_{r}} I_{d s} \\
\dot{\omega}_{m}=\frac{1}{J}\left[\psi_{d r} I_{q s}-T_{m}\right]
\end{array}\right.
$$

Regulation of Ids current: Equation 18.b, gives the expression of $\psi_{d r}$ as:

$$
\psi_{d r}=\frac{\tau_{l} L_{l}}{\alpha}\left(\dot{I}_{d s}+\frac{1}{\tau_{l}} I_{d s}-V\right)
$$

where $V=\omega_{s} I_{q s}+\frac{1}{L_{1}} V_{d s}$ was the control input function.

Equation (19) shows that $\psi_{d r}$ depends only on the $I_{d s}$ current.

The derivative of Eq. 18.b was:

$$
\ddot{I}_{d s}=\frac{\alpha}{\tau_{1} L_{1}} \dot{\psi}_{d r}-\frac{1}{\tau_{1}} \dot{I}_{d s}+\dot{V}_{1}
$$

By substituting Eq. 18.c and Eq.(19) in Eq. (20), we obtain

$$
\begin{aligned}
\ddot{I}_{d s} & =-\left(\frac{1}{\tau_{r}}+\frac{1}{\tau_{l}}\right) \dot{I}_{d s}-\left(\frac{1}{\tau_{r} \tau_{l}}-\frac{L_{m} \alpha}{\tau_{r}^{2} L_{l}}\right) I_{d s}+U_{f} \\
& =-A_{f} \dot{I}_{d s}-B_{f} I_{d s}+U_{f}
\end{aligned}
$$

Where $U_{f}=\frac{1}{\tau_{r}} V+\dot{V}$ was the new control function.

Let $e_{i}=I_{d s}-I_{d s_{-} r e f}$ : the error on $I_{d s}$ current. We can write: $\dot{e}_{i}=\dot{I}_{d s}$.

Application of the sliding mode: The implementation of a variable structure regulator consists on the application of a control function (describe in the system (22)) for render the system insensitive against parameters variations ${ }^{[23,20]}$.

$$
U_{i}=\left\{\begin{array}{ccc}
U_{i}^{+}(x, t) & \text { if } & S_{i}>0 \\
U_{i}^{-}(x, t) & \text { if } & S_{i}<0
\end{array}\right.
$$

Where $S_{i}$ was the $i$ th component of a switching surface $S_{i}=0$.

This system with discontinuous control was called variable structure system, since the control structure switches alternatively according to the state of the system. The sliding mode occurs on a switching surface $S_{i}(x)=0$, which forces the original system to behave as linear time invariant system, which can be considered to be stable.

In our study the surfaces were taken to be linear and written as :

$$
\begin{gathered}
S_{f}=c_{l} e_{i}+\dot{e}_{i} \\
c_{1}=\text { constant }
\end{gathered}
$$

The design of such a system involves ${ }^{[26][23]}$ :

(i) The choice of the control function $U_{i}$ to guarantee the existence of a sliding mode.

(ii) The determination of the switching function $S$ such that the system has the desired response.

(iii) The elimination of chattering of the control signal.

\section{Control function}

$\dot{S}_{f}$ was given by

$$
\dot{S}_{f}=-\left(A_{f}-c_{1}\right) \dot{I}_{d s}-B_{f} I_{d s}+U_{f}
$$

Let

$$
\left\{\begin{array}{l}
A_{f}=A_{f n}+\Delta A_{f} \\
B_{f}=B_{f n}+\Delta B_{f}
\end{array}\right.
$$

Here $A_{f n}$ and $B_{f n}$ were the nominal values, and $\Delta A_{f}$ and $\Delta B_{f}$ were the associated variations.

Let the control function $U_{f}$ be decomposed into

$$
U_{f}=U_{f_{e q}}+\Delta U_{f}
$$

Where $U_{f e q}$, called the equivalent control, was defined as the solution of the problem $S^{\prime}=0$ under $A_{f}=A_{f n}$, $B_{f}=B_{f n}$. That was :

$$
U_{f_{e q}}=\left(A_{f n}-c_{1}\right) \dot{I}_{d s}+B_{f n} I_{d s}
$$

The function $\Delta U_{f}$ was the discontinuous term, employed to eliminate the influence due to $\Delta A_{f}$ and $\Delta B_{f}$ so as to guarantee the existence of sliding mode was constructed as :

$$
\Delta U_{f}=\lambda_{f 1} \dot{I}_{d s}+\lambda_{f 2} I_{d s}+\lambda_{f 3}\left|S_{f}\right|
$$

It was known that the condition of the existence and reachability of a sliding motion was ${ }^{[22,27]}$

$$
\dot{S}_{f} S_{f}<0
$$

Substitution of Eqs (25),(26) and (27) into Eqn (24) yields

$\dot{S}_{f}=\left(\lambda_{f 1}-\Delta A_{f}\right) \dot{I}_{d s}+\left(\lambda_{f 2}-\Delta B_{f}\right) I_{d s}+\lambda_{f 3}\left|S_{f}\right|$

Then

$$
\begin{aligned}
S_{f} \dot{S}_{f}= & \left(\lambda_{f 1}-\Delta A_{f}\right) \dot{I}_{d s} S_{f}+\left(\lambda_{f 2}-\Delta B_{f}\right) I_{d s} S_{f} \\
& +\lambda_{f \dot{s}}\left|S_{f}\right| S_{f}
\end{aligned}
$$


Then the condition for satisfying inequality $\dot{S}_{f} S_{f}<0$ were :

$$
\begin{aligned}
& \lambda_{f 1}=\left\{\begin{array}{lll}
\lambda_{f 1}^{+}<\min \left(\Delta A_{f}\right) & \text { if } & S_{f} \dot{I}_{d s}>0 \\
\lambda_{f 1}^{-}>\max \left(\Delta A_{f}\right) & \text { if } & S_{f} \dot{I}_{d s}<0
\end{array}\right. \\
& \lambda_{f 2}=\left\{\begin{array}{lll}
\lambda^{+}{ }_{f 2}<\min \left(\Delta B_{f}\right) & \text { if } & S_{f} I_{d s}>0 \\
\lambda_{f 2}^{-}>\max \left(\Delta B_{f}\right) & \text { if } & S_{f} I_{d s}<0
\end{array}\right. \\
& \lambda_{f 3}=\left\{\begin{array}{lll}
\lambda_{f 3}^{+} & \text {if } & S_{f}>0 \\
\lambda_{f 3}^{-} & \text {if } & S_{f}<0
\end{array}\right.
\end{aligned}
$$

Then the quantities $\lambda_{f 1}, \lambda_{f 2}$ and $\lambda_{f 3}$ could be chosen as follows

$$
\left\{\begin{array}{l}
\lambda_{f 1}=\lambda^{+}{ }_{f 1}=-\lambda_{f 1}^{-} \\
\lambda_{f 2}=\lambda^{+}{ }_{f 2}=-\lambda_{f 2}^{-} \\
\lambda_{f 3}=\lambda^{+}{ }_{f 3}=-\lambda_{f 3}^{-}
\end{array}\right.
$$

The control law $\Delta U_{f}$ can be expressed as

$$
\Delta U_{f}=\left(\lambda_{f 1} \dot{I}_{d s}+\lambda_{f 2} I_{d s}+\lambda_{f 3}\left|S_{f}\right|\right) \operatorname{sgn}\left(S_{f}\right)
$$

Regulation of angular speed: The equations used for regulating the angular speed were written in the following

$$
\begin{aligned}
& \dot{I}_{q s}=-\frac{\alpha}{L_{1}} \omega_{m} \psi_{d r}-\omega_{s} I_{d s}+\frac{1}{\tau_{1}} I_{q s}+\frac{1}{L_{1}} V_{q s} \\
& \dot{\omega}_{m}=\frac{1}{J}\left[\frac{L_{m}}{L_{m}+L_{r}}\left(\psi_{d r} I_{q s}\right)-T_{m}\right]
\end{aligned}
$$

From the Eqs (35) we wirte :

$$
\ddot{\omega}_{m}=\frac{1}{J}\left[\frac{L_{m}}{L_{m}+L_{r}}\left(\psi_{d r} \dot{I}_{q s}\right)-\dot{T}_{m}\right]
$$

The elimination of the state variable $I_{q s}$ and by the substitution of Eqs (35), (34) in Eqs (36) gives the following differential equation in $\omega_{m}$

$$
\begin{aligned}
& \ddot{\omega}_{m}=-\frac{1}{\tau_{1}} \dot{\omega}_{m}-\frac{L_{m} \alpha \psi_{d r}^{2}}{J\left(L_{m}+L_{r}\right) L_{1}} \omega_{m}-\frac{1}{J \tau_{1}} T_{m} \\
&+\frac{L_{m} \psi_{d r}}{J\left(L_{m}+L_{r}\right)}\left(\frac{V_{q s}}{L_{1}}-\omega_{s} I_{d s}\right) \\
& \text { Or } \ddot{\omega}_{m}=-A_{v} \dot{\omega}_{m}-B_{v} \omega_{m}-C_{v} T_{m}+U_{v}
\end{aligned}
$$

Where $\quad U_{v}=\frac{L_{m} \psi_{d r}}{J\left(L_{m}+L_{r}\right)}\left(\frac{V_{q s}}{L_{1}}-\omega_{s} I_{d s}\right)$ represent the control input.

The error on the angular speed was written $e_{v}=\omega_{m}-\omega_{\text {ref }}$ and $\dot{e}_{v}=\dot{\omega}_{m}$

Where $\omega_{\text {ref }}$ was the desired angular speed. In the same way, the switching surface was chosen:
Let

$$
S_{v}=c_{2} e_{v}+\dot{e}_{v}
$$

$$
\dot{S}_{v}=c_{2} \dot{e}_{v}+\ddot{e}_{v}=c_{2}\left(\omega_{m}-\omega_{r e f}\right)+\ddot{\omega}_{m}
$$

And we substitute $\ddot{\omega}_{m}$ by it expression, we obtain :

$$
\dot{S}_{v}=-\left(A_{v}-c_{2}\right) \dot{\omega}_{m}-B_{v} \omega_{m}-C_{v} T_{m}+U_{v}
$$

Let us consider

$$
\left\{\begin{array}{l}
A_{v}=A_{v n}+\Delta A_{v} \\
B_{v}=B_{v n}+\Delta B_{v} \\
C_{v}=C_{v n}+\Delta C_{v}
\end{array}\right.
$$

Let the control function $U_{v}$ was constructed as

$$
U_{v}=U_{v e q}+\Delta U_{v}
$$

The equivalent control $U_{v e q}$ was build as follows

$$
U_{v e q}=\left(A_{v}-c_{2}\right) \dot{\omega}_{m}+B_{v} \omega_{m}+C_{v} T_{m}
$$

And the discontinuous control was

$$
\Delta U_{v}=\lambda_{v 1} \dot{\omega}_{m}+\lambda_{v 2} \omega_{m}+\lambda_{v 3}\left|S_{v}\right|
$$

Substituting Eqn. (42), (43) and (44) in (41), we obtain

$$
\dot{S}_{v}=\left(\lambda_{v 1}-\Delta A_{v}\right) \dot{\omega}_{m}+\left(\lambda_{v 2}-\Delta B_{v}\right) \omega_{m}+\lambda_{v 3}\left|S_{v}\right|
$$

To satisfy the sliding condition $\dot{S}_{v} S_{v}<0^{[23]}$, it was sufficient to take :

$$
\begin{aligned}
& \lambda_{v 1}=\left\{\begin{array}{llc}
\lambda^{+}{ }_{v 1}<\min \left(\Delta A_{v}\right) & \text { if } & S_{v} \dot{\omega}_{m}>0 \\
\lambda^{-}{ }_{v 1}<\max \left(\Delta A_{v}\right) & \text { if } & S_{v} \dot{\omega}_{m}<0
\end{array}\right. \\
& \lambda_{v 2}=\left\{\begin{array}{lll}
\lambda^{+}{ }_{v 2}<\min \left(\Delta B_{v}\right) & \text { if } & S_{v} \omega_{m}>0 \\
\lambda^{-}{ }_{v 2}<\max \left(\Delta B_{v}\right) & \text { if } & S_{v} \omega_{m}<0
\end{array}\right. \\
& \lambda_{v 3}=\left\{\begin{array}{lll}
\lambda^{+}{ }_{v 3}<\min \left(\Delta C_{v} T_{m}\right) & \text { if } & S_{v}>0 \\
\lambda^{-}{ }_{v 3}<\max \left(\Delta C_{v} T_{m}\right) & \text { if } & S_{v}<0
\end{array}\right.
\end{aligned}
$$

\section{Chattering}

For the control law given by Eqs. (42), if $\lambda_{v k}$, $k=1,2,3$ were chosen as : $\lambda_{v k}=\lambda^{+}{ }_{v k}=-\lambda_{v k}^{-}$then the discontinuous control function $U_{v}$ can be represented as $\Delta U_{v}=\left(\lambda_{v 1} \dot{\omega}_{m}+\lambda_{v 2} \omega_{m}+\lambda_{v 3} \mid S_{v}\right) \operatorname{sign}\left(S_{v}\right)$

Since the control $U_{v}$ contains the sign function, direct application of such a control signal to the motor may give rise to chattering. To reduce the chattering, the sign function $\operatorname{sign}\left(S_{v}\right)$ in the Eqn.(47) can be replaced by modified proper continuous function ${ }^{[27]}$ as :

$\frac{S_{v}}{\left|S_{v}\right|+\delta}$ where $\delta$ was chosen as a function of $\left|\omega_{m}-\omega_{\text {ref }}\right|$ as $\delta=\varepsilon_{0}+\varepsilon_{1}\left|\omega_{m}-\omega_{\text {ref }}\right|$ and the value of $\varepsilon_{0}$ and $\varepsilon_{1}$ were positive constants. 


\section{RESULTS AND DISCUSSION}

The Simulink/Matlab software package implementation was adopted because its inherent integration of vectorized system representations, time graphical portrayal of signals combined evolutions and the simple functionality realization of the controllers and power electronic excitations.

The motor parameters were given in Table 1 and they were identified in the last work ${ }^{[28]}$.

Table 1: Induction motor parameters

\begin{tabular}{ll}
\hline Parameters & Value \\
\hline $\mathrm{R}_{\mathrm{r}}$ & $29 \Omega$ \\
$\mathrm{R}_{\mathrm{s}}$ & $10 \Omega$ \\
$\mathrm{L}_{\mathrm{r}}$ & $680 \mathrm{mH}$ \\
$\mathrm{L}_{\mathrm{s}}$ & $690 \mathrm{mH}$ \\
$\mathrm{L}_{\mathrm{m}}$ & $660 \mathrm{mH}$ \\
$\mathrm{J}$ & $0.00062 \mathrm{Kg} \cdot \mathrm{m}^{2}$ \\
Number of Poles P & 1 Pair of poles \\
Power & $370 \mathrm{~W}$ \\
\hline
\end{tabular}

The simulation of the inputs to the machines involves the mathematical representation of programmed time sequence of events such as the sudden application or removal of mechanical loads, the ramping of the magnitude and frequency of the applied voltages, or even the changes in parameter values (for instance $R_{r}$ and $R_{s}$ ).

Preparation phases : Fig. 3 and 4 show the evolution of flux and $I_{d s}$ current during the preparation of the motor to the field-oriented control. The analysis of these figures leads to the classification of the time space into three phases. It was to be noted that during these phases, $\omega_{s}$ was maintained equal to zero.

$\mathbf{1}^{\text {st }}$ phase : corresponds to the application of the control $V_{d s}=V_{d s \max }$ until Ids reaches 1.2 times its nominal value. In this case, the motor was described by Eqs. (13).

$2^{\text {nd }}$ phase : in this phase, the control law giving the expression of $V_{d s}$ was described by Eqs (14), which corresponds to the maintaining of $I_{d s}$ current equal to 1.2 times of its nominal value, until $\psi_{d r}$ reaches its nominal value.

$3^{\text {rd }}$ phase : start at $0.12 \mathrm{~s}$. At this time we apply the control law leads to maintain the flux $\psi_{d r}$ equal to its reference value. (Fig 2 to 5)

Start up: We note that we can apply the desired input speed after $0.2 \mathrm{~s}$ (when the motor was ready).

One chose to apply the reference speed after $1 \mathrm{~s}$.

In order to test the robustness of the proposed method, we simulated the control strategy using PID and sliding mode. For both cases, we excited the simulator with the same input variables (consign angular speed and perturbation). Results were illustrated by Fig. 6 .

It can be see that the sliding mode offers a robust control compared to PID control manly when applying a load torque to the system (from instant 2 and 4.5s)

To show the performance of the proposed structure at varying operation ranges, we introduce a random variation on the stator and rotor resistances (this internal disturbance was due to the internal temperature variation of the motor). Moreover we applies the torque load between $\mathrm{t}=2 \mathrm{~s}$ and $4,5 \mathrm{~s}$ with $10 \%$ of incertitude Fig 7.

The influence of the load variation applied between $\mathrm{t}=$ $2 \mathrm{~s}$ and $4.5 \mathrm{~s}$ was illustrated on Fig. 8 and 9.

It was clear that the chattering on the control signal was decreased when we replaced the sign function by a continuous function Fig. 10 and 11.

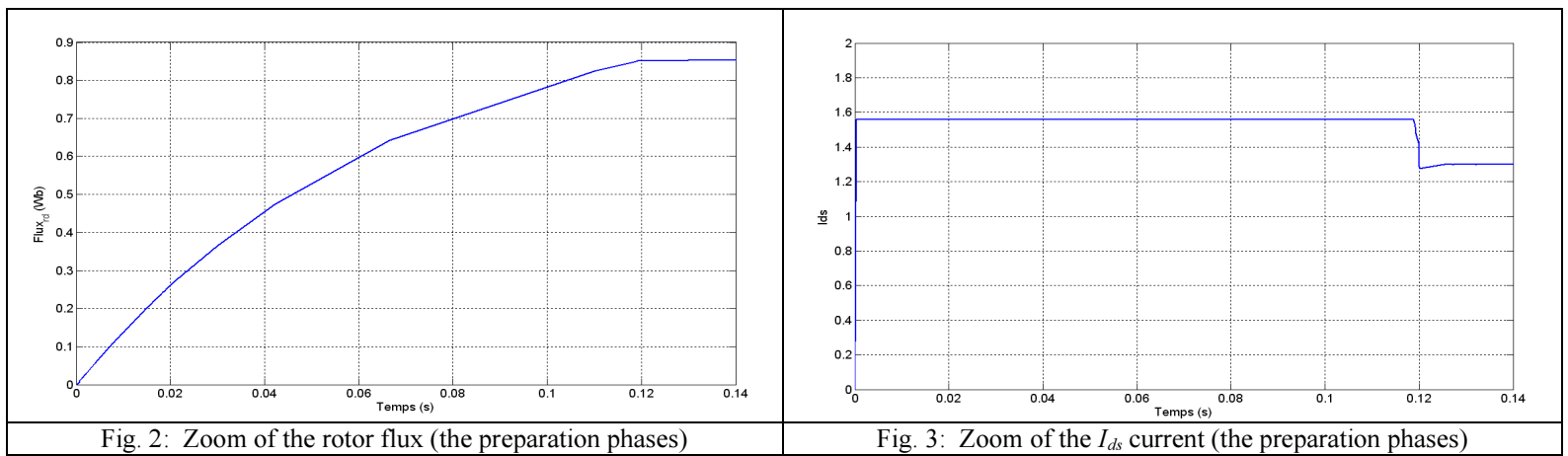




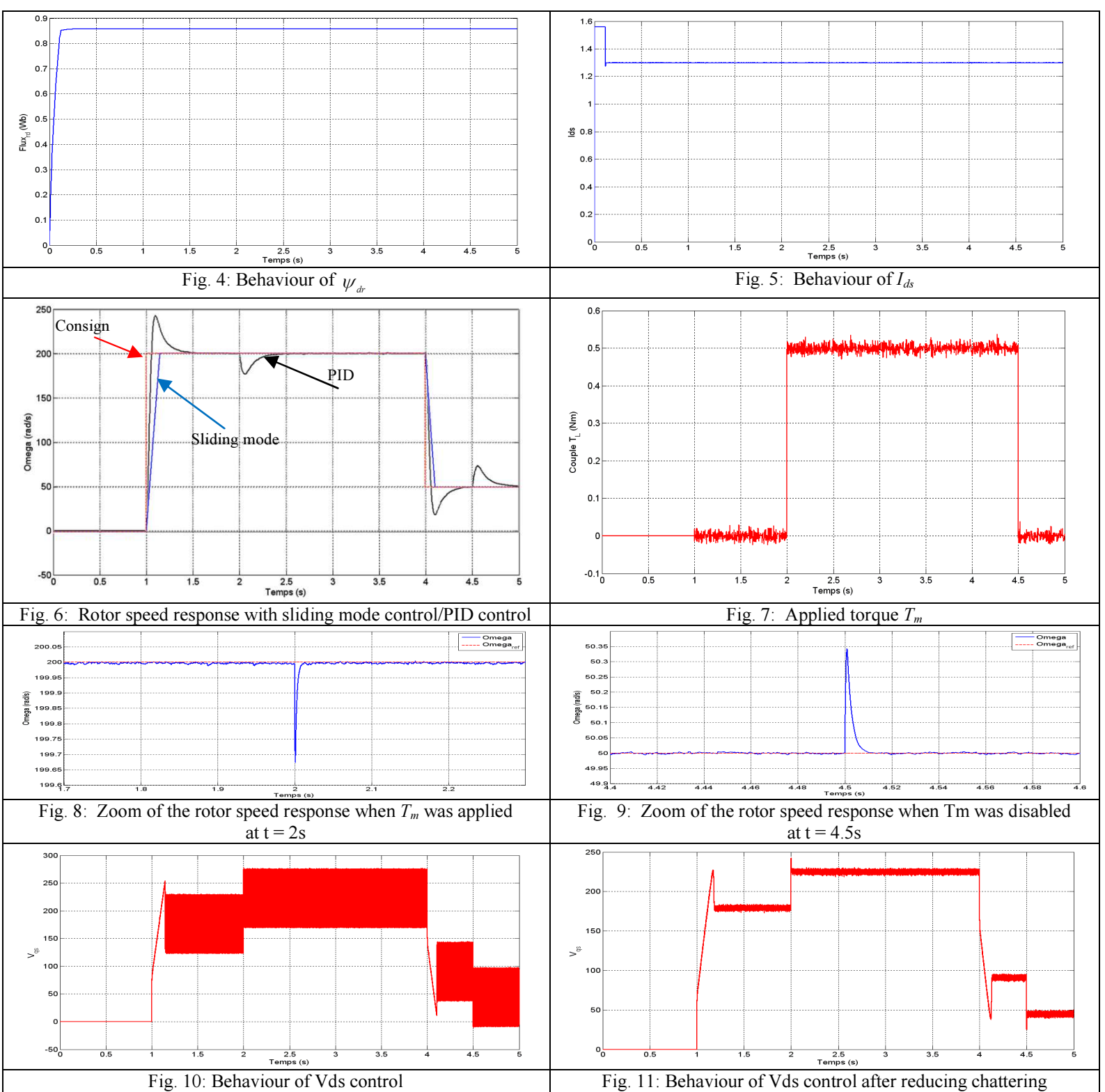

\section{CONCLUSION}

The field-oriented control using a sliding mode speed was employed to obtain the better performance from the induction motor in a speed control. Also, compared to the classical PID control, a sliding mode approach gives a rather accurate response in face of large plant parameter variations and external disturbances.
In ours future study, we will interest to test our algorithm on an experimental plant composed of a $0.37 \mathrm{~kW}$ induction motor. The command was designed with a digital signal processor TMS320F240 board.

\section{REFERENCES}

1. J. Wang, S. S. Get and T. H. Lee, 2000. Adaptive Fuzzy Sliding Mode Control of a Class of Nonlinear Systems. Proceeding of the $3^{\text {rd }}$ Asian Control Conference, Shanghai, pp: 599-604. 
2. Ta-Tau Chen and Tzuu-Hseng S. Li, 2000. Integrated Fuzzy GA-Based Simplex Sliding-Mode Control. International Journal of Fuzzy Systems, 2 (4): $267-277$.

3. S. Belkhodja B. de Fornel, 1996. Commande adaptative d'une machine asynchrone. J. Phys. III, 6 : 779-796.

4. MINH TA CAO, 1997. Commande numérique de machines asychrones par logique floue, Thesis, School of Science Québec, University LAVAL, 1997.

5. Cristian Lascu, Ion Boldea and Frede Blaabjerg, 2004. Direct Torque Control of Sensorless Induction Motor Drives: A Sliding-Mode Approach. IEEE Transactions on Industry Applications, 40 (2): 582590.

6. H. Sarhan and R. Issa, 2006. Improving Mechanical Characteristics of Inverter-induction Motor Drive System. American Journal of Applied Sciences, 3 (8): 1961-1966.

7. T. Brahmananda Reddy, J. Amarnath and D. Subba Rayudu, 2006. Direct Torque Control of Induction Motor Based on Hybrid PWM Method for Reduced Ripple: A Sliding Mode Control Approach. ACSE Journal, 6 (4): 23-30.

8. R.Toufouti S.Meziane ,H. Benalla, 2006. Direct Torque Control for Induction Motor Using Fuzzy Logic. ACSE Journal, 6 (2): 17-24.

9. I. Takahashi and Y. Ohmori, 1989. Highperformance direct torque control of induction motor. IEEE Trans. Ind. Appl, 25 (2):257-264.

10. F. Blaschke, 1972. The principle of field orientation as applied to the new transvector closed-loop control system for rotating field machine. Siemens Rev., 39, pp: 217-220.

11. M. Djemai, J. Hernandez and J.P. Barbot, 1993. Nonlinear Control with Flux Observer for a Singularly Perturbed Induction Motor. Proceeding of the 32nd Conference on Decision and Control, Texas, pp: 3391-3396.

12. R. J. Wai, 2000. Adaptive sliding-mode control for induction servo motor drive. IEE Proc. Elect. Power Application 147 (6): 533-562.

13. Rong-Jong Wai and Kuo-Min Lin, 2005. Robust Decoupled Control of Direct Field-Oriented Induction Motor Drive. IEEE Transactions on Industrial Electronics, 52 (3): 837-854.

14. V. I. Utkin, 1993. Sliding mode control design principle and application to electric drives. IEEE Trans. Ind. Electron., 40 (1): 23-36.
15. L. G. Shiau and J. L. Lin, 2001. Stability of slidingmode current control for high performance induction motor position drives. IEE Proc. Elect. Power Applicat., 148 (1): 69-75.

16. R. J. Wai and W. K. Liu, 2001. Nonlinear decoupled control for linear induction motor servo-drive using the sliding-mode technique. IEE Proc. Contr. Theory Applicat.,148 (3): 217-231.

17. M. Kuchar, P. Brandstetter and M. Kaduch, 2004. Sensorless induction motor drive with neural network. PESC, Aachen Germany, pp: 3301-3305,

18. Qinghui $\mathrm{Wu}$ and Cheng Shao, 2006. Novel Hybrid Sliding-mode Controller for Direct Torque Control Induction Motor Drives. Proceedings of the American Control Conference Minneapolis, Minnesota, USA, pp: 2754-2758.

19. T. Ourth, 1993. Commande vectorielle d'un moteur asynchrone sans capteur. J. Phys. III France 3, pp : 1123-1133

20. V.1 Utkin, 1978. Sliding mode and their application in variable structure systems. Moscow.

21. A. Levant, 1993. Sliding order and sliding accuracy in sliding mode control. Int. J. Control, 58: 12471263.

22. G. Bartolini, A. Ferrara, E. Usai, and V. Utkin, 2000. On multi-input chattering-free second-order sliding mode control. IEEE Trans. Automat. Control, 45 (9): 1711-1717.

23. M. Ouali, M.B.A. Kamoun, 1997. Field-oriented control induction machine and control by sliding mode. Simulation Practice and Theory 5: 121-136.

24. A. Mansouri, M. Chenafa, A. Bouhenna, E. Etien, 2004. Powerful Nonlinear Observer Associated With Field-Oriented Control Of an Induction Motor. Int. J. Appl. Math. Comput. Sci, 14 (2): 209-220.

25. Franck Morand, 2005. Techniques d'observation sans capteur de vitesse en vue de la commande des machines asynchrones. Thesis, National School Of Applied Sciences Of Lyon. 2005.

26. Utkin, V.I., 1977. Variable structure systems with sliding mode, IEEE Trans., AC-22: 212-222.

27. T.-L. Chern and Y.-C. Wu, 1993. Design of brushless DC position servo systems using integral variable structure approach. IEE Proceedings-B, 140 (1): 27-34.

28. K. JAMOUSSI, M. OUALI, H. CHARRADI, 2006. Reconstructeur d'état d'un moteur asynchrone par DSP. Proceeding of the seventh International Conference on Science and Techniques of Automatic control STA, 2006 RME-028, pp: 1:11. 